\title{
Estrategias de intensificación en el discurso de docentes de primaria sobre diversidad sexual y funcional
}

Intensification strategies of primary teachers discourse about sexual and functional diversity

\author{
Volumen 19, Número 1 \\ Sección Especial \\ Enero-Abril \\ pp. 1-31
}

Este número se publica el 1 de enero de 2019

DOI: 10.15517/aie.v19i1.35580

Daniel Fernández Fernández

Revista indizada en REDALYC, $\underline{\text { SCIELO }}$

Revista distribuida en las bases de datos:

LATINDEX, DOAJ, REDIB, IRESIE, CLASE, DIALNET, SHERPA/ROMEO, QUALIS-CAPES, MIAR

Revista registrada en los directorios:

ULRICH'S, REDIE, RINACE, OEI, MAESTROTECA, PREAL, CLACSO 


\section{Estrategias de intensificación en el discurso de docentes de primaria sobre diversidad sexual y funcional}

Intensification strategies of primary teachers discourse about sexual and functional diversity

\section{Daniel Fernández Fernández ${ }^{1}$}

Resumen: El presente artículo analiza las estrategias de intensificación en el discurso de docentes de primaria sobre diversidad sexual y funcional. Las estrategias de intensificación constituyen un mecanismo pragmalingüístico mediante el cual los hablantes establecen un determinado nivel de cercanía en el marco de una interacción comunicativa. Metodológicamente, se desarrolla un abordaje de carácter cualitativo abocado a tres procesos: la identificación y la descripción de los recursos de intensificación a nivel del enunciado y la elaboración de inferencias discursivas mediante una articulación teórico- analítica. Los resultados del proceso de investigación reflejan que la búsqueda, de acuerdo con el oyente, constituye un mecanismo para hacer creíble lo dicho y, en la misma dirección, una forma para resguardar la propia imagen (fachada) que, concomitantemente, refleja las dificultades por parte del personal docente en lo que respecta al abordaje de la diversidad sexual y funcional.

Palabras clave: diversidad sexual, diversidad funcional, intensificación, lingüística, pragmática.

Abstract: The present paper analyses the intensification strategies used by the primary school teachers discourse about sexual and functional diversity. Intensification strategies constitutes a pragmalinguistic mechanism through which the speaker stablish a certain level of proximity in the frame of a particular communicative interaction. Methodologically, the article proposes a qualitative approach based on three different processes: the identification and description of intensification resources in the enunciative setting and the elaboration of discursive inferences throughout an analytical theoretical articulation. The results of the research process show that the tendency of trying to achieve a mutual agreement with the interlocutor, represents a mechanism to make the elocutions believable and, in the same direction, a way to protect the self-image (front) that, concomitantly, reflects the difficulties that the teachers have approaching sexual and functional diversity.

Key words: sexual diversity, functional diversity, intensification, linguistics, pragmatics.

\footnotetext{
${ }_{1}$ Profesor e Investigador de la Universidad de Costa Rica.

Dirección electrónica: danielfernand@gmail.com
}

Documento recibido: 9 de julio, 2018

Enviado a corrección: 2 de octubre, 2018

Aprobado: 29 de octubre, 2018 


\section{Introducción}

Los resultados presentados en este artículo forman parte de una tesis de Maestría en Lingüística titulada "Estrategias de atenuación e intensificación en el discurso de docentes de primaria sobre diversidad sexual y funcional". Tanto dicha investigación como los resultados presentados aquí se estructuran a partir de dos conjuntos básicos de elementos, uno lingüístico (estrategias de atenuación e intensificación) y otro social (educación y diversidad), que también se podrían caracterizar como procedimientos micro-discursivos y macrodiscursivos.

El abordaje global de estos elementos permite dilucidar la relación discursiva que las personas docentes establecen con las temáticas propuestas, consideración particularmente relevante en esta investigación, pues, a pesar de que en la actualidad existen importantes avances en materia de derechos humanos respecto a la población sexualmente diversa y con diversidad funcional (muchos de los cuales se expresan en leyes y decretos nacionales e internacionales suscritos por el país), a nivel sociocultural persisten visiones estereotípicas sobre estas poblaciones, las cuales limitan el alcance de tales avances. Esto, debido, en gran medida, a que sus características físicas y/o comportamentales no corresponden a los cánones de normalidad establecidos por nuestra sociedad (Conte y Zamora, 2008).

Una premisa que sustenta este trabajo es que la cultura occidental de la cual formamos parte conlleva una serie de atribuciones en torno a la corporalidad ${ }^{2}$, que determinan el estatus de normalidad de una persona, las cuales concomitantemente condicionan las posibilidades que tiene un sujeto para establecer lazos sociales. De acuerdo con Van Dijk (1990), el discurso manifiesta y al mismo tiempo modela las múltiples propiedades de la situación sociocultural que denominamos su contexto. En este sentido, interesa abordar un escenario social concreto, como son las escuelas primarias del sistema de instrucción pública costarricense, con el acometido de aprehender el discurso que maneja el personal docente en relación con las dimensiones de la diversidad antes referidas. El discurso se materializa a través de diversas realizaciones lingüísticas, y el presente texto se centra en las estrategias e intensificación como la vía para examinar dicho discurso.

De esta forma, el estudio presentado aquí se aboca a responder la siguiente pregunta de investigación: ¿Cómo operan las estrategias de intensificación en el discurso de docentes

\footnotetext{
2 Hablamos de corporalidad y no simplemente de cuerpo, para implicar que no se trata simplemente de características físicas que los cuerpos efectivamente poseen o que le son atribuidas, sino también del conjunto de relaciones que están puestas en juego para el establecimiento de la dupla normalidad - anormalidad.
} Volumen 19 Número 1 (Enero-Abril), ISSN 1409-4703 
de primaria del sistema de educación pública costarricense en torno a la diversidad sexual y funcional?

\section{Referentes teóricos}

\subsection{Diversidad sexual y funcional}

Se emplea el concepto de diversidad funcional, el cual surge especialmente en España como una vía de autorreconocimiento que se contrapone al carácter estigmatizante que conlleva el término discapacidad. Mediante la enunciación del concepto de diversidad funcional se alude: "a una realidad en la que la persona funciona de manera diferente o diversa de la mayoría de la sociedad. Este término considera la diferencia de la persona y la falta de respeto de las mayorías, que en sus procesos constructivos no tienen en cuenta esa diversidad funcional" (Palacios y Romañach, 2006, p. 108). Por su parte, la diversidad sexual es entendida desde los planteamientos de la teoría queer, la cual parte de una crítica a la heteronormatividad (la idea de que la heterosexualidad es la forma natural y correcta de relacionarse) y la cissexualidad (la idea de que debemos identificarnos con la denominación biológica que nos fue asignada al nacer), como ejes fundamentales para subtender el sistema hegemónico sexo - género (Fernández, 2016).

Existe una relación estrecha desde el punto de vista genealógico respecto al tridente género/sexualidad - discapacidad - educación. Cada uno de estos componentes alcanzó una prominencia en el sistema mundo occidental en periodos históricos bastante próximos, siendo que tanto la retórica médica en torno a la sexualidad y discapacidad como el modelo educativo prusiano (Gatto, 2001), proliferaron en el seno de la razón centro europea de los siglos XVIII y XIX. Estrechamente relacionado con la cuestión de las condiciones psíquicas de la subjetividad, está la preocupación acerca de los límites corpóreos de la subjetividad. Para Grosz (1996), la manera en que el cuerpo es vivido y representado, así como los acercamientos y efectos de la corporalidad del sujeto en su identidad, parecen aspectos cruciales, a pesar de ser usualmente factores desestimados en cualquier explicación sobre el sujeto.

Davis (2000) señala que la discapacidad es una relación socialmente determinada hacia el cuerpo que fue relativamente organizada en los siglos XVIII y XIX y propulsada por factores económicos y sociales, como parte de un proyecto más general de control y regulación del cuerpo. Para Davis, dichos análisis encajan con otros aspectos de la regulación del cuerpo que hemos llegado a nombrar crimen, sexualidad, género, 
enfermedad, subalternidad, entre otras. La escuela, al conformar un aspecto central en el engranaje de la sociedad contemporánea, ha constituido un agente activo en ese proceso de control y regulación del cuerpo, que opera en mayor o menor medida en determinados aspectos de la subjetividad.

En esta línea, el estudio de McRuer (2006) identifica las formas en que la demanda cultural de producir estudiantes que tengan habilidades medibles y que escriban de manera ordenada, está conectada a las demandas compulsivas de heterosexualidad y capacitismo corporal que habitamos ordenadamente, y que conllevan identidades coherentes o dirigidas. La noción de normalidad representa un aspecto clave en la aproximación de McRuer. Para este, la heterosexualidad compulsiva está entrelazada con el capacitismo corporal en la medida en que ambos sistemas trabajan para (re)producir el cuerpo capacitado y la heterosexualidad.

Existen paralelismos en cómo se ha conceptualizado y discriminado a quienes excedían las normas sexuales y capacitistas que generan un espacio de "normalidad". Así, por ejemplo, el paso del modelo de la prescindencia (conformado por los submodelos eugenésico y de marginación), pasando por el modelo rehabilitador, hasta llegar al modelo social y de los derechos humanos (Palacios, 2006) en lo que respecta a la discapacidad, resulta análogo al recorrido de aprehensión institucionalizante que ha permeado a las personas sexualmente diversas.

De manera reciente, se han empezado a vislumbrar algunos factores homólogos que permiten establecer nexos respecto a la configuración del cuerpo funcionalmente diverso (Crip Theory) y el cuerpo sexualmente diverso (Queer Theory). La presente investigación busca incorporar el caudal teórico de estos abordajes al análisis/interpretación de las concepciones que maneja el personal docente sobre la diversidad sexual y funcional en relación con su ámbito de trabajo.

Con el objetivo de cernir tales concepciones, optamos por hacer énfasis en las estrategias pragmalingüísticas de intensificación presentes en el discurso del profesorado sobre diversidad sexual y funcional, entendiendo que dichas estrategias, al conllevar un aumento en la expresión de significado (asociado tanto a la intención de reforzar la imagen del "yo" como a ejercer una influencia en el interlocutor), constituyen una vía plausible para captar las concepciones que maneja el personal docente sobre las temáticas objeto de estudio. 


\subsection{Estrategias de intensificación}

En esta investigación entendemos, partiendo de los planteamientos de Briz (2003), que la intensificación representa una categoría pragmática que está vinculada a actividades estratégicas que desarrollan las personas hablantes, la cual afecta la intencionalidad de los enunciados y tiene a su vez una impronta en las relaciones interpersonales y sociales de los sujetos implicados en su enunciación. Una dificultad mayor, para el estudio de la intensificación, reside en el hecho de que existen múltiples términos para dar cuenta de un conjunto de fenómenos que entran en el espectro de la intensificación. Por ejemplo, se habla de énfasis (González, 1984), expresividad (Herrero, 1991), realce lingüístico (Ferrer y Sánchez, 1998), gradación (Martín, 1998)³, entre otros conceptos que resultan bastante próximos al espectro antes referido.

Así, de acuerdo con Arce (1999), el intensificador es entendido como mecanismo de reforzamiento que conlleva una afectación semánticamente que produce cambios o variaciones de significado en el término al que acompañan, pero también desde el punto de vista pragmático, pues tienen una impronta a nivel de las actitudes o valoraciones de los interlocutores, en los que intervienen factores extralingüísticos como el contexto, la intención del hablante, los gestos, el tono de voz empleado y las inferencias que se producen en el interlocutor.

Dada la multiplicidad de acercamientos que existen en torno a este constructo y al traslape de nociones -que si bien conjugan referentes teóricos que resultan próximos o colindantes-, estas no están necesariamente cohesionadas. Por esta razón, hemos optado por fundamentar nuestra propuesta en los trabajos del Grupo de Investigación Val.Es.Co. (Valencia, Español, Coloquial), en este caso, centrándose principalmente en los aportes de la autora Marta Albelda. Para Albelda (2005), es necesario visualizar dos vertientes, en lo que se refiere a la comprensión de la intensificación, una correspondiente al ámbito del enunciado, y la otra, al ámbito de la enunciación. En lo que respecta al primero, "se ha entendido como un valor semántico del contenido proposicional manifestado gramaticalmente de diversas formas" (p. 26), lo cual supone una modificación de la cantidad y/o de la cualidad en el significado de algunas categorías gramaticales. Mientras que, en la segunda vertiente, la correspondiente a la enunciación, prominentemente se ha hablado de la intensificación como el refuerzo de la aserción.

\footnotetext{
${ }^{3}$ Estas referencias fueron ubicadas gracias al trabajo de Albelda (2005). Se incluyen aquí únicamente los textos que se pudieron obtener mediante el servicio de bases de datos (Dialnet y EBSCO). Volumen 19 Número 1 (Enero-Abril), ISSN 1409-4703
} 
Por otra parte, la intensificación constituye un fenómeno escalar y por lo tanto "no se puede entender como una categoría clasificatoria, sino comparativa, relativa: un elemento que se explica comparativamente es un elemento escalar. Algo se ve intensificado con respecto a algo que no lo está; en este sentido, la intensificación requiere la existencia de un punto de referencia" (Albelda, 2004, p. 107).

Sobre este aspecto, conviene profundizar la forma en que la autora concibe que se da la relación entre la intensificación y su significado a nivel del enunciado, para la cual indica que "el enunciado intensificado señala cuál es el punto a partir del cual se establece la intensificación porque lo entraña en su significado escalar" (Albelda, 2004, p. 108). De esta forma, los elementos más débiles que aparecen en el enunciado funcionan como puntos de referencia, brindando la clave pare el reconocimiento de los elementos intensificados.

Cabe decir, por demás, que la intensificación puede actuar en el ámbito proposicional y en el modal. De acuerdo con Albelda y Álvarez (2010), en función de la incidencia enunciativa, se puede hablar de:

- Intensificación en el ámbito proposicional o del dictum: se configura sobre un elemento de la proposición.

- Intensificación en el ámbito de la modalidad o modus: entendiéndola en sentido amplio, que incluye las modalidades oracionales, apreciativas y lógicas (epistémica y deóntica).

Por otra parte, conviene señalar que la intensificación es también una de las manifestaciones pragmáticas de la cortesía valorizante, en tanto que, "la intensificación surge como mecanismo de filiación pragmática entre los interlocutores, lo que dentro de la Teoría de la Cortesía representa un máximo grado de afinidad entre estos” (Hidalgo, 2011, p. 275). Una vez planteados los distintos factores que se relacionan con el acto pragmático que conlleva intensificar, procedemos ahora a brindar una definición del concepto de intensificación, el cual resumimos, se refiere a:

(...) una estrategia evaluativa del contenido proposicional o de la modalidad. En parte está codificada en la lengua y, a su vez, refuerza la implicación del hablante en la comunicación e imprime un grado mayor de compromiso con lo dicho que, en consecuencia, produce efectos a nivel comunicativo y social. Este fenómeno no se definirá solo como un valor semántico, sino como un aspecto perteneciente al plano de la expresión, puesto que el hablante emplea una serie de formas lingüísticas para ponerlas al servicio de sus propósitos comunicativos. (Albelda, 2005, p. 188) 
Como se puede colegir a partir de esta definición, el carácter implicacional y estratégico destacan como aspectos pragmáticos claves en la compresión de las estrategias intensificadoras, aspecto que consideramos decisivo para la comprensión del discurso del personal docente, objeto del presente estudio.

En esta línea, conviene enfatizar que el aumento o disminución en la expresión del significado está asociado, de acuerdo con Montecino (2004), a diferentes finalidades comunicativas: 1) constituye una estrategia para que el "yo" refuerce la verdad de lo expresado; 2) permite que el hablante haga valer su intención de habla en forma coconstructiva, o bien, 3) ejerce influencia en el interlocutor en tanto juego de imágenes. De acuerdo con el autor, estos fines parten del supuesto de que todo acto de habla representa una amenaza y, en consecuencia, el mismo debería asumirse como un acto de poder.

\section{Metodología}

La presente investigación tiene un enfoque cualitativo, por cuanto privilegia la profundidad y el análisis fino como vías fundamentales para alcanzar la validez científica. De acuerdo con Reguera (2008), el enfoque cualitativo es un proceso sistemático que conlleva la identificación del significado y comprensión de la realidad. En este sentido, la decisión de decantarse por un acercamiento cualitativo responde justamente a la conjunción de aspectos tales como significados, contexto e interpretación, aspectos que desde nuestro punto de vista resultan imprescindibles para dar cuenta del problema de investigación aquí planteado.

Este artículo se realiza mediante un corpus de entrevistas perteneciente al proyecto "Diversidad sexual y diversidad funcional: La (re)producción de subalternidades en el sistema educativo costarricense" (№ 724-B4-349), llevado a cabo por parte del autor del presente artículo, durante el periodo 2014-2016 en el Instituto de Investigación en Educación de la Universidad de Costa Rica.

Para el desarrollo de este artículo se trabajó con un corpus de 10 entrevistas, la determinación de dicha cantidad se definió a partir de un criterio experto esgrimido por el investigador del grupo VALESCO, Antonio Briz, quien, a la luz de la formulación del problema de investigación propuesto, recomendó trabajar con el número entrevistas antes referido. (Antonio Briz, comunicación personal, 10 de mayo de 2016). Para un entendimiento adecuado de las estrategias de intensificación estudiadas, se especifican, a continuación, los procedimientos utilizados en el manejo del material: 


\subsection{Ubicación de los procedimientos de intensificación a nivel del enunciado}

Este subproceso se aboca a la ubicación discursiva del intensificador en el miembro discursivo al que afecta. Como señalan Albelda, Briz, Cestero, Kotwica y Villalba (2014), el concepto de posición es relativo, pues se refiere a una 'posición respecto a algo', y en el caso del fenómeno discursivo, dicha posición debe medirse en un contexto interaccional concreto. Para ello, extrapolamos la propuesta de Albelda et al. (2014) sobre el marcaje de los elementos discursivos atenuantes al caso de los intensificadores, como se muestra a continuación:

- Elemento causante o desencadenante: El contexto interaccional causante o desencadenante de la intensificación (subrayado estándar).

- Elemento o segmento intensificador: Recurso, táctica empleada para intensificar (se marcará en negrita).

- Elemento o segmento intensificado: Miembro discursivo al que afecta el elemento intensificador. Se refiere a la acción que conviene intensificar (se marcará en cursiva).

\subsection{Tipificación de las funciones que conllevan los recursos de intensificación identificados}

Una vez identificados los procedimientos de intensificación empleados por las personas hablantes, así como su ubicación dentro de los enunciados, se pasa a identificar sus funciones comunicativas. Para ello se siguió la tipología planteada a por Albelda (2005):

- Función 1: Hacer más creíble lo dicho: Reforzar la verdad de lo dicho para asegurar que lo dicho es una información relevante y garantizarse a sí mismo la aceptación de su mensaje por parte de las personas oyentes.

- Función 2: Imponer el yo: Imponer el punto de vista personal ya sea directamente, o bien a través de la imposición de lo dicho.

- Función 3: Buscar el acuerdo en el oyente: conseguir que el oyente esté de acuerdo y se alinee con el hablante, o, por otro lado, intensificar el conflicto con el oyente.

\section{Análisis de resultados}

A continuación, se hará una descripción de cada uno de los recursos identificados (ver Tabla 1), presentando ejemplos específicos de cada mecanismo, en los cuales aparece marcado, según corresponda, el elemento causante o desencadenante, el segmento intensificado y el elemento o segmento intensificante. Posteriormente, se aborda la función Volumen 19 Número 1 (Enero-Abril), ISSN 1409-4703 
de los intensificadores en el enunciado y se establecen inferencias discursivas a nivel de la enunciación respecto a la actividad estratégica y la construcción de imagen. Al hablar inferencias discusivas, se hace referencia al proceso interpretativo que consiste en poner en relación lo dicho explícitamente con otra cosa distinta de lo dicho, o, en otros términos, se refiere a la información presupuesta en un enunciado, que implicará una determinada acción o efecto de sentido que en este caso es interpretado de acuerdo a las funciones que cumplen los recursos de intensificación utilizados (Charaudeau y Maingueneau, 2002).

Tabla 1

Listado de recursos lingüísticos de intensificación

Recursos segmentales
Recursos suprasegmentales
Unidades simples: Sustantivos
Unidades simples: Adjetivos
Unidades simples: Verbos
Unidades simples: Adverbios
Enunciados fraseológicos

Locuciones

Enumeraciones

Esquemas sintácticos

Repeticiones

Modificadores simples: Adverbios

Modificadores simples: Numerales

Tropos: Símil

Fuente: Elaboración propia, 2017.

\subsection{Recursos segmentales: Alargamientos fonéticos}

Conviene tomar algunas precauciones cuando se trata de analizar propiedades relacionadas con la fonación, pues, como señala Hidalgo (2015), uno de los aspectos más problemáticos para la descripción de las partículas discursivas es su capacidad de matización a través de las propiedades fónicas, las cuales no constituyen situaciones aisladas o esporádicas, sino comportamientos constantes asociados a factores pragmáticos específicos.

En este trabajo entendemos que los mecanismos fónicos atañen a todos los procedimientos pragmalingüísticos que fueron identificados en el corpus de estudio, dado que la oralidad constituye el sustrato material de los fenómenos lingüísticos objeto de análisis. En esta sección se contemplan específicamente los fenómenos fonéticos del alargamiento vocálico y consonántico.

Partimos de que "el fenómeno del alargamiento segmental aparece como un universal lingüístico que, presente en lenguas de diversas características, pareciera tener comportamientos sistémicos que cambiarán dependiendo de factores pragmáticos, ilocutivos, expresivos" (Cid y Malenda, 2005, p. 45) y dentro de esos factores destacamos la intensificación, como una vía para marcar un énfasis discursivo. 
Partimos del planteamiento según el cual, el hablante, al considerar necesario realzar alguna dimensión de un segmento discursivo, realiza una focalización que se materializa en el alargamiento segmental. La noción de foco se refiere a "un punto en el que confluyen los vectores intencionales del emisor. Su propósito comunicativo suele ser llamar la atención del receptor a fin de vencer en este una predisposición contraria o simplemente de subrayar su importancia en el proceso informativo en el que nos hallamos inmersos" (Gutiérrez, 2000, p. 34).

Pasamos ahora a ver los ejemplos correspondientes a los ejes temáticos del estudio:

(1) es que hay discapacidades hay muchas (.) hay personas que están com:pletamente sanas (.) y tienen discapacidades (-) eh no sé (.) por medio de inseguridades (.) temores (.) que tiene todas sus capacidades mentales (.) psíquicas (.) físicas (.) y aun así no no (.) no: no hacen cosas por miedos (.) temores (.) por depresiones por situaciones que son ya (.) internas verdad (.) $\{$ P10.3 $\}$

[Provincia: Heredia] [Sexo: Mujer] [Diversidad: Funcional]

(2) bueno vea yo en (.) todo lo que es diversidad sexual (.) soy una persona sumamente amplia (.) de to:da la vida (.) verdad (.) este (.) viví en un hogar en donde a nosotros se nos enseñó a respetar todas las cosas (.) de los demás (.) nos gustaran o no nos gustaran $\{P 6.16\}$

[Provincia: San José] [Sexo: Mujer] [Diversidad: Sexual]

En todas las intervenciones, los alargamientos están referidos a segmentos léxicos, con un carácter ilocutivo diferenciable para cada uno de ellos. La hablante que interviene en (1), al señalar que "hay personas que están completamente sanas y tienen discapacidades", acentúa el nexo entre discapacidad y enfermedad, que se puede observar a partir del quiasma que se infiere de la intervención de la docente: hay personas que están completamente sanas $\rightarrow$ y tienen discapacidades y hay personas con discapacidades $\rightarrow$ (ergo) que no están completamente sanas. En ambos casos, la función del mecanismo de intensificación consiste en buscar el acuerdo con el oyente con lo dicho.

Por su parte, en (2), la entrevistada hace alusión a su forma de comprender y abordar el tema de la diversidad, el cual describe como "amplio" y lo caracteriza a su vez como algo 
de "to:da la vida". En este caso, la función intensificadora del alargamiento vocálico se refiere a hacer más creíble lo dicho, que además es reforzada por los otros mecanismos de intensificación que aparecen en la intervención.

\subsection{Recursos suprasegmentales}

Los procedimientos prosódicos o suprasegmentales intervienen en la intensificación de los significados y, de acuerdo con Albelda (2005), pueden hacerlo de dos modos, superponiéndose a otros procedimientos lingüísticos o actuando individualmente de manera aislada, es decir, que a los fenómenos de intensificación morfosintácticas, léxicas y semánticas, pueden sumarse elementos prosódicos peculiares que contribuyen a la intensificación, pero también es posible obtener este valor en construcciones que no presentan ningún otro rasgo de intensificación mediante la acción de la entonación.

El realce constituye también aquí el aspecto clave que permite comprender el valor que adquiere este mecanismo. "Para otorgar relieve particular a una palabra o a una parte del enunciado, los hablantes utilizan el denominado acento enfático, contrastivo o de insistencia. El acento enfático asigna prominencia al elemento enunciado que se quiere destacar" (RAE, 2011, p. 425).

Continuando con el planteamiento de la $\operatorname{RAE}$ (2011), desde el punto de vista semántico, el acento enfático al recaer en un elemento o segmento específico de un enunciado, tiene una función contrastiva, dado que aclara cuál es elemento más sobresaliente de aquello que ha sido dicho. Desde el punto de vista fonético, tiene lugar mediante una destacada elevación del tono fundamental que marca un contraste importante con los otros elementos de la secuencia.

Partiendo de estos principios generales, pasamos a revisar algunos ejemplos extraídos del corpus, según cada una de las clasificaciones sobre diversidad.

(3) yo siento que: que: (.) estamos fallando (.) muy bien los niños hay que insertarlos en el proceso (.) pero entonces (.) $\underline{\text { mínimo que nos pongan }}$ una asistente (.) mientr:as uno por lo menos se adapta y el niño (.) se adapta al sistema $\{P 1.9\}$

[Provincia: San José] [Sexo: Mujer] [Diversidad: Funcional] 
(4) entonces qué digo (.) que deberían no sé en qué forma ubicarse (.) y decir (.) en el caso de nosotros especiales (.) yo soy de artes industriales (.) de hecho hasta tengo un proyecto de hacer un torno pequeñito (.) así en madera (.) portables (.) para que trabajen (.) yo simplemente NO VOY a poder trabajar con ciertas discapacidades en eso (.) con ellos (.) y se lo pierden (.) porque yo tengo dos lecciones (.) e:h a la semana $\{P 3.6\}$

[Provincia: San José] [Sexo: Hombre] [Diversidad: Funcional]

(5) nosotros estuvimos por recibir a una niña con (.) con Síndrome de Down (.) pero al final no sé qué fue lo que pasó y no vino (.) pero nosotros ya nos habíamos preparado para recibirla (.) y le digo todos (.) toda la escuela (.) verdad $\{$ P6.31\}

[Provincia: San José] [Sexo: Mujer] [Diversidad: Funcional]

En la intervención (3), las palabras destacadas apuntan a hacer manifiesto el descontento de la docente con el sistema educativo en relación con las condiciones ofrecidas para integrar al estudiantado con características funcionales especiales. De forma similar, el docente que habla en (4), describe la relación entre lo que concibe como los recursos disponibles y sus posibilidades de acción respecto al estudiantado con discapacidad, la oración "no voy a poder trabajar con ciertas discapacidades", con acento en el segmento "no voy", permite enfatizar en la oposición manifestada por el entrevistado. Finalmente, en (5), la intervención versa sobre el accionar de la institución en el caso de una niña con Síndrome de Down; a partir del realce del segmento "todos, toda la escuela", se pretende enfatizar el carácter colectivo del abordaje desarrollado. Por lo tanto, se puede aducir que a través del mecanismo empleado se busca resaltar una imagen positiva del trabajo que realiza la institución.

En lo que respecta al terreno de la diversidad sexual, la búsqueda de acuerdo con el oyente constituye la constante en los siguientes ejemplos:

(6) [respecto a las personas homosexuales] también hay mucho más riesgo en parte de enfermedades y así (.) por su condición de (.) cambian de pareja en pareja en la sexualidad (.) y cosas así que hay riesgo bastante altos (.) igual hay gente que es fiel (.) pero la mayoría NO es así \{P3.25\}

[Provincia: San José] [Sexo: Hombre] [Diversidad: Sexual] Volumen 19 Número 1 (Enero-Abril), ISSN 1409-4703 
(7)

(.) e:h (.) no sé: con respecto a los estudiantes (.) he tenido experiencias en otros años donde (.) uno de viaje ve (.) ${ }^{p}$ y uno dice bueno este chiquito $^{p}$ (.) yo le veo toda la pinta de gay verdad (.) que uno dice $\{P 5.18\}$

[Provincia: San José] [Sexo: Mujer] [Diversidad: Sexual]

(8) e:h yo he tenido casos en otra escuela (.) de una mamá que le hablamos de un caso de un niño así (.) y: por ejemplo no le gustaba jugar futbol con los amigos pero él era (.) ÉL ERA LA: PO:RR:ISTA (.) del grupo de los chiquitos (.) y le hacía porras a todos (.) entonces imagínese los problemas en la clase $\{\mathrm{P} 7.14\}$

[Provincia: San José] [Sexo: Mujer] [Diversidad: Sexual]

(9) hay conducta de hombres y mujeres que es muy marcada (.) y tiene mucho que ver con el machismo entonces MUY normal que las niñas estén jugando casita (.) haciendo comida (.) muy normal que los niños estén jugando carros (.) pero eh (.) a pesar de eso (.) o que los niños sean violentos y las niñas como sutiles (.) eso es muy normal $\{$ P8.15\}

[Provincia: Heredia] [Sexo: Mujer] [Diversidad: Sexual]

En (6), el entrevistado brinda su percepción de lo que considera que conlleva ser una persona homosexual, una "condición" que describe como un riesgo venéreo inminente, del cual hace la salvedad, está exenta la "gente que es fiel", pero seguidamente rectifica diciendo que "la mayoría no es asi", con acento enfático en la negación. A través del realce, se busca acrecentar tanto la verosimilitud de la visión que tiene la persona docente sobre la homosexualidad como la plausibilidad de su posicionamiento moral.

En la intervención (7), tenemos una combinación de recursos de atenuación e intensificación, necesarios para alcanzar los logros comunicativos que persigue la entrevistada. Destacamos aquí lo tocante a la intensificación, que se presenta cuando la docente señala "este chiquito, yo le veo toda la pinta de gay"; mediante el relieve tonal, se enfatiza un aspecto relacionado con una estereotipia que atañe a la percepción visual y supone decir que hay algo de lo "gay" ("la pinta") que se aprecia a simple vista. 
En (8), se hace referencia a un niño que no cumple con las expectativas del rol masculino de género ("no le gustaba jugar futbol con los amigos"). La intensificación (tanto segmental como suprasegmental), aparece en el momento en el que se indica que el niño además de incurrir en este incumplimiento, actúa de forma diametralmente opuesta a lo que dicta el canon de género ("él era la porrista del grupo de los chiquitos").

Finalmente, en (9), hay una superposición de procedimientos lingüísticos de intensificación, dado que "muy", actúa ya de por sí en la frase como un modificador adverbial. A diferencia de los ejemplos anteriores, los procedimientos de intensificación son utilizados por la entrevistada para subrayar de manera crítica la persistencia del estatus quo en los roles de género.

\subsection{Enunciado fraseológico}

La función de realce constituye igualmente un aspecto importante en la caracterización de este mecanismo, en tanto que, las unidades fraseológicas

"pueden emplearse en los procesos argumentativos, ya sea en secuencias argumentativas propiamente, ya en la argumentación general de la conversación. Su papel no consiste únicamente en actuar como elementos de unión, del mismo modo que los conectores pragmáticos, sino en servir de realce de la argumentación" (Ruiz, 1998, p. 42).

A continuación, presentamos los ejemplos respectivos:

(10) digamos si yo me pongo a hablar ahí en el grupo (-) cómo se hace el amor por ejemplo (.) entonces algunos niños si se los permiten hasta la mamá ya les ha hablado de eso (.) pero otros no (.) entonces es una bronca que usted se compra que no es jugando verdad $\{\mathrm{P} 1.22\}$

[Provincia: San José] [Sexo: Mujer] [Diversidad: Sexual]

(11) entonces yo siempre me he ido por ahí [por la vía de la inclusión] (.) porque eso es pan de todos los días y de toda mi vida (.) yo siempre he visto gente (.) e:h heterosexuales (.) homosexuales (.) eh bi:sexuales (.) yo me he topado con gente BISEXUAL (.) que no es que ha tenido nada conmigo pero (.) se lo cuentan a uno $\{$ P5.32\}

[Provincia: San José] [Sexo: Mujer] [Diversidad: Sexual] Volumen 19 Número 1 (Enero-Abril), ISSN 1409-4703 
En (10), la entrevistada se refiere a la complejidad que supone el abordaje de temáticas relacionadas con educación sexual, asociada especialmente -según su criterio- a la interferencia de los padres de los estudiantes; la forma de dar cuenta de la magnitud de dicha dificultad, es mediante la frase "comprar(se) una bronca que no es jugando", cuya función es mostrar la plausibilidad del punto de vista esgrimido y obtener el acuerdo del interlocutor.

Por su parte, en (11), la docente se presenta a sí misma como una persona muy inclusiva en lo que respecta a temas relacionados con la diversidad sexual y centra su intervención en hacer ver que este posicionamiento constituye una actitud generalizable a lo largo de su vida. El enunciado "eso es pan de todos los días", permite intensificar el balance que la docente realiza sobre su propia labor.

\subsection{Locuciones}

Cuando se habla de locuciones, "frecuentemente se trata de sintagmas prepositivos que, por cuestiones de índole semántica o funcional, parecían tener cierta relación con la categoría del adverbio" (Corpas, 1997, p. 99). Las locuciones identificadas en el corpus de estudio constituyen sintagmas que funcionan como complementos circunstanciales con un carácter intensificador. Presentamos a continuación algunos ejemplos:

(12) con este chiquito [estudiante con distrofia muscular] (.) entonces yo le enseñé a los alumnos (.) a los estudiantes en aquel momento (.) a respetar (.) a querer (.) a ayudar (.) e:h fomenté un montón de valores con ellos y ellos lo hacían $\downarrow\{P 5.15\}$

[Provincia: San José] [Sexo: Mujer] [Diversidad: Funcional]

muchas veces son tan tremendas y tan profundas [las discapacidades asociadas a trastornos emocionales] que (.) por ejemplo que no pueden aprender a leer (.) no pueden escribir (.) no te pueden entender un montón de cosas $\downarrow$ (.) y supuestamente son niños normales $\{\mathrm{P} 6.8\}$

[Provincia: San José] [Sexo: Mujer] [Diversidad: Funcional] 
(14) yo le voy a ser muy sincera (.) yo creo que dios creo a un hombre y una mujer verdad $\downarrow$ (.) este y que sí hay personas pues que hay (.) tal vez por una cuestión genética (.) que que (.) puedan tener ahí alguna otra este (.) inclinación (.) yo respeto montones verdad (.) ahora toda I (.) todo este boom de la diversidad sexual que hay (.) $\{\mathrm{P} 9.12\}$

[Provincia: Heredia] [Sexo: Mujer] [Diversidad: Sexual]

Las fórmulas "un montón de + SUSTANTIVO" y "VERBO + montones", son locuciones adverbiales y por lo tanto tienen la misma función gramatical que un adverbio, es decir, acompañar verbos, adjetivos y otros adverbios. En (12), y (13), el recurso es utilizado para reforzar la verdad de lo dicho, que en este caso se refiere a las cualidades o en general los aspectos positivos que las personas entrevistadas identifican respecto a su propia labor como docentes, a saber, el nivel de preparación respecto a situaciones problemáticas (acoso escolar), el fomento de valores y el respeto a la diversidad, respectivamente.

Mientras tanto, en (14) la construcción es empleada para buscar el acuerdo por parte del interlocutor, haciendo aquí referencia a las dificultades educativas que tienen los estudiantes que presentan trastornos emocionales: "no te pueden entender un montón de cosas y supuestamente son niños normales". En esta intervención es importante destacar la función argumentativa que tiene la locución: "no entender un montón de cosas" representa una condición que antagoniza con lo que se considera "normal" a nivel educativo.

\subsection{Unidades simples}

Este mecanismo se categoriza dentro de lo que se conoce como intensivos léxicos, en los cuales el elemento reforzante se identifica en todo el lexema y funciona a través de un procedimiento léxico semántico o léxico-sintáctico (Penas, 2009, p. 231). De acuerdo con Albelda (2005), existen distintas posibilidades de intensificación dentro de este tipo de categoría:

- Algunas sustituyen el significado de otras palabras a las que incluyen, pues tienen un sema de mayor intensidad y por lo tanto su significado se define relativamente (ejemplo: encantar es 'gustar mucho').

- Otras no tienen un término equivalente en menor intensidad, ya que de por sí, son lexemas que denotan intensificación (ejemplo: abominable). 
- Hay otras en las que no se sustituye un significado cualitativo sino solo el de 'grande' + ‘muy' (ejemplo: gigantesco).

\subsubsection{Adjetivo}

El caso particular del adjetivo supone una cuantificación de la cualidad o una intensificación del grado (Fuentes, 2006). A continuación, veremos ejemplos de este mecanismo para las categorías de contenido del estudio

el asunto es más bien institucional $\downarrow$ (.) o sea lejos de ver al alumno relegado (.) o sea alguna habilidad tiene que nos puede enriquecer a todos (.) no necesariamente porque no va bien en las materias (.) porque no sale bien en los exámenes (.) es que no sirve (.) o que no tiene nada que aportarnos $\downarrow$ (.) es es un giro completo $\{\mathrm{P} 2.11\}$

[Provincia: San José] [Sexo: Hombre] [Diversidad: Funcional]

no sé si me tocará verlo [diversidad sexual] con algún niño (.) eh en su forma (.) total (.) porque no me ha tocado (.) cómo yo reaccionaría $\uparrow$ (.) porque cuando lo que tengo que hacer hacia un adulto hacia un joven (.) mi aceptación hacia la persona es total $\downarrow$ (.) no sé si está bien usado (.) porque me cuesta (-) acep:tar (.) esa parte $\{$ P4.12\}

[Provincia: San José] [Sexo: Mujer] [Diversidad: Sexual]

En (15), el entrevistado habla de la necesidad de comprender de una manera diferente la situación del estudiantado que muestra un bajo rendimiento académico, destacando la necesidad de visibilizar otras de sus habilidades. El docente describe ese cambio de mirada como un "giro completo"; en este caso se evidencia que la significación se define relativamente, pues se relaciona con el nivel alcanzado por el "giro".

Mientras tanto, en (16), tenemos el adjetivo "total", que es utilizado por parte de la consultada para auto-calificar su nivel de aceptación de las personas con una orientación o identidad sexual no hegemónica. El contraste de esta declaración con el señalamiento final brindado por la docente ("me cuesta, aceptar, esa parte"), muestra el valor que tiene el uso del recurso léxico de intensificación a nivel de la imagen proyectada por parte de la entrevistada, su utilización faculta su inscripción dentro de los márgenes de la deseabilidad social. 


\subsubsection{Adverbio}

La intervención que se presenta a continuación muestra el uso del adverbio "totalmente" como un intensivo léxico:

(17) hay discapacidades que no son sólo esas (.) en este caso a niveles motores (.) sino que también hay este (.) hay unas que son de trastorno emocional $\downarrow$ (.) y esas son las que menos está tocando atender (.) porque totalmente anulan al estudiante (.) a la persona (.) para poder realizar las cosas normalmente $\{\mathrm{P} 6.8\}$

[Provincia: San José] [Sexo: Mujer] [Diversidad: Funcional]

La docente hace referencia a los efectos que conllevan los trastornos de índole emocional, los que señala, "anulan al estudiante, a la persona”. El verbo "anular", que a nivel semántico implica por sí mismo una forma de realce de las consecuencias, se ve aquí doblemente incrementado por la anteposición del adverbio, lo cual acrecienta la verosimilitud del enunciado.

\subsubsection{Verbo}

En la siguiente intervención se muestra el ejemplo de un intensivo léxico verbal:

$$
\text { tuvimos el caso de un chico ahí que } \downarrow \text { (.) ya le había gustado mucho el }
$$
papel $\uparrow$ de que (.) la víctima soy yo (.) entonces más bien toreaba a los compañeros para ver qué me va a decir $\uparrow\{\mathrm{P} 2.22\}$

[Provincia: San José] [Sexo: Hombre] [Diversidad: sexual]

En este caso, el verbo "torear", utilizado en el sentido de "provocar" o "molestar", le permite al docente valorar el accionar del estudiante al que se hace mención, el cual estima como inadecuado. La imagen del "toro" justamente pone en relieve la inadecuación de la conducta referida.

\subsubsection{Sustantivo}

Para concluir esta sección, en (19) tenemos un ejemplo relacionado con el uso del sustantivo: 
los maestros que tenemos mucho tiempo de estar aquí (.) que participamos en el proceso [Programa de Inclusión Educativa] (.) este (.) sentimos eso sí la necesidad (.) y fue una de las cosas que pasó (.) de ir abordando todo este reguero de cosas que se generaron a partir de (.) una situación tan tremenda como es la inclusión educativa que (.) ya le había contado (.) lo de la discapacidad (.) la diversidad (.) todo asociado a la UNESCO $\{$ P6.26 $\}$

[Provincia: San José] [Sexo: Mujer] [Diversidad: Funcional]

En esta intervención, la entrevistada hace alusión al cambio que considera que produjo la participación de varios docentes en un Programa de Inclusión Educativa, el cual explica, supuso abordar un "reguero de cosas", asociadas al tópico que enuncia dicho programa. En este caso el sustantivo "reguero", implica resaltar que los aspectos relacionados con la inclusión educativa son múltiples y variados, así como también confusos (este último elemento referido al uso específico que según el DRAE tiene este sustantivo en Costa Rica).

\subsection{Enumeración}

La enumeración constituye "otra forma de ponderar, de subrayar o reforzar en un proceso comunicativo" (Arce, 1999, p. 44).

(20) yo tengo sólo DOS lecciones (.) con cada grupo (.) por semana $\downarrow$ (.) muy poco (.) me viene alguien discapacitado se me hace difícil (.) hay un grupo de treinta (.) hay un grupo de veintiocho de veintiséis de veinte $\{\mathrm{P} 3.5\}$

[Provincia: San José] [Sexo: Hombre] [Diversidad: Funcional]

(21) yo tuve un alumno con distrofia muscular progresiva (.) él ya murió (.) pero ese chiquito a mí me tocó ir a ver (.) cómo lo manejaba yo en el aula y todo (.) a pesar de los apoyos $\uparrow$ (.) no son suficientes $\downarrow$ (.) para todo lo que hay que hacer con ellos durante el día la semana el mes y durante todo el año $\{\mathrm{P} 6.6\}$

[Provincia: San José] [Sexo: Mujer] [Diversidad: Funcional] 
entonces yo no sé si es ya por mi edad (.) por mis creencias (.) que desde niña me inculcaron (.) pero: (.) a mi hogar llegan [personas sexualmente diversas] (.) y se sienten amados (.) respetados (.) aceptados (.) y de hecho regresan una y mil una vez (.) porque saben que ahí tienen todo eso $\{\mathrm{P} 4.13\}$

[Provincia: San José] [Sexo: Mujer] [Diversidad: Sexual]

Como es previsible, los aspectos realzados en cada ejemplo varían de acuerdo con los fines pragmáticos que tiene cada hablante en cada caso. En la intervención (20), el hablante hace mención de las dificultades que desde su perspectiva conlleva el trabajo con estudiantes con discapacidad, específicamente para la materia de artes industriales. Destaca en primera instancia la falta de tiempo y en un segundo momento habla del número de estudiantes por aula: "un grupo de treinta, hay un grupo de veintiocho, de veintiséis, de veinte".

En una línea similar, la docente en (21) habla de las exigencias que conlleva el abordaje de la discapacidad en la labor educativa, pero no en abstracto, sino más bien refiriéndose a la experiencia de un estudiante concreto con distrofia muscular progresiva. En este caso la intensificación se orienta a subrayar los requerimientos para trabajar con dicho estudiante a través de la enumeración de distintos rangos temporales: "durante el día, la semana, el mes y durante todo el año".

Finalmente, en el ejemplo (22), la entrevistada hace referencia a su relación con personas cuya orientación e identidad sexual no se inscribe en los parámetros sexuales de la heteronormatividad y/o la cisgeneridad. La docente describe el sentir que dichas personas experimentan en relación a ella: "se sienten amados, respetados, aceptados". En todos estos ejemplos, el mecanismo de enumeración, al representar una vía para reforzar la argumentación y para sopesar diversos puntos de vista, tiene la función de buscar el acuerdo por parte del oyente en relación a lo dicho.

\subsection{Esquema sintáctico}

De este mecanismo identificamos un único ejemplo en el corpus, referido al tema de la diversidad funcional. De acuerdo con Albelda (2005), se trata de estructuras que presentan una determinada combinación de categorías gramaticales que favorece la creación de un valor intensificador a nivel discursivo. 
(23) he tenido muchísimos pero muchísimos estudiantes (.) le puedo decir que lo que tengo cuarenta y siete años de ser maestra (...) este es mi año cuarenta y siete (.) y en estos cuarenta y siete años yo he tenido más de treinta estudiantes (.) este (.) con problemas desde muy mínimos hasta muy graves $\{\mathrm{P} 6.10\}$

[Provincia: Urbana] [Sexo: Mujer] [Diversidad: Funcional]

En (23) se emplean otros recursos de intensificación (sufijo, repetición), mediante los cuales la entrevistada destaca la cantidad de años de servicio y el hecho de que ha tenido muchos estudiantes con distintos niveles de marcación funcional. Para hacer referencia a este último aspecto, la docente utiliza la estructura "desde... hasta", para generar este realce en el que ubica "mínimo" en el punto de origen y "grave" en el punto límite.

\subsection{Repetición}

Respecto a este recurso cabe destacar, que "un enunciado adquiere fuerza e intensidad mediante la repetición, bien de un sintagma, bien de un único término. En un diálogo se consigue el mismo resultado enfático con las construcciones-eco". (Arce, 1999, p. 43). En las intervenciones que aparecen a continuación se muestran ejemplos de ambos tipos de repeticiones:

(24) entonces (.) eso al Ministerio no le importa ellos n- no hacen el estudio cómo debe ser entonces (.) nada más sacan los niños de la Centeno (.) los sacaron los sacaron (.) los reubicaron $\{\mathrm{P} 1.12\}$

[Provincia: San José] [Sexo: Mujer] [Diversidad: Funcional]

(25) pero también a veces es complicado (.) verdad y: y: diay uno trata (.) más que está en el proceso verdad de formación (.) pero ese sí es un tema [diversidad sexual] ya (.) muy delicado (.) muy delicado $\{$ P7.15\}

[Provincia: San José] [Sexo: Mujer] [Diversidad: Sexual] 
(26) yo he visto (.) he tenido chiquitas que solo juegan con hombres y solo futbol y futbol y futbol (-) y: nunca las ve usted con una coli:ta ni nada (.) pero di (.) yo las he dejado (.) de hecho alguna: de ellas tal vez llegue a la selección (.) verdad (.) de fútbol: más adelante $\{P 1.35\}$

[Provincia: San José] [Sexo: Mujer] [Diversidad: Sexual]

En (24) y en (25), tenemos lo que de acuerdo con Roca y Suñer (1998) cabría llamar reduplicación de tipo discursivo, la cual consiste "en la repetición de una unidad o serie de unidades para añadir un valor enfático a todo el enunciado" (p. 44-45). En el primer caso, la docente manifiesta su descontento respecto al hecho de sacar a estudiantes de la Escuela Fernando Centeno Güell (reiterando el sintagma "los sacaron"), para ubicarlos en Instituciones del sistema educativo regular.

En el segundo caso, la repetición se emplea para reforzar la valoración que realiza la docente sobre lo que supone que es la diversidad sexual, la cual designa como un tema "muy delicado" En este caso el reforzamiento es doble, dada la presencia del adverbio "muy" dentro del sintagma reduplicado.

Por su parte, en (26) tenemos una reduplicación léxica, que en este caso consiste "en la repetición de una única palabra como mecanismo para obtener un valor de intensificación o cuantificación sobre una propiedad, una acción o un objeto" (Roca y Suñer, 1998, p. 47). En dicha intervención se pone en juego una contraposición relacionada con la designación de género otorgada a diferentes actividades. Se plantea así el siguiente contraste:

Tabla 2

Comparación de roles de género

\begin{tabular}{|c|c|}
\hline Rol femenino & Rol masculino \\
\hline $\begin{array}{c}\text { "(chiquitas a las que) nunca las } \\
\text { ve usted con una colita ni nada" }\end{array}$ & $\begin{array}{c}\text { "chiquitas que solo juegan con } \\
\text { hombres y solo futbol y futbol y } \\
\text { futbol" }\end{array}$ \\
\hline
\end{tabular}

Fuente: Elaboración propia, 2017.

De esta forma, la reiteración de la palabra "futbol" constituye una forma de reforzar el antagonismo de los roles de género. 


\subsection{Modificadores simples}

De acuerdo con Albelda (2005), el valor de intensificación no solo puede encontrarse en elementos que poseen funciones nucleares, sino también elementos modificadores. "Los intensificadores equivalen, en general, a las estructuras "muy + adjetivo/adverbio" y "mucho + sustantivo", en tanto que la función por excelencia de los modificadores es la que prestan los adjetivos y los adverbios" (p. 91-92). Destacamos aquí dos tipos de modificadores: los numerales y el más frecuente, los adverbios.

\subsubsection{Numeral}

Este mecanismo comprende las expresiones en las que, mediante una cifra, se pretende rebasar el límite de lo que se considera habitual.

(27) entonces yo digo que hay una parte muy importante que es el afecto (.) creo en eso cien por ciento (.) después de eso todo lo que uno se pueda capacitar $\downarrow\{\mathrm{P} 4.9\}$

[Provincia: San José] [Sexo: Mujer] [Diversidad: Funcional]

(28) por mis creencias (.) que desde niña me inculcaron (.) pero: (.) a mi hogar llegan [personas sexualmente diversas] (.) y se sienten amados (.) respetados (.) aceptados (.) y de hecho regresan una y mil y una vez (.) porque saben que ahí tienen todo eso \{P4.13\}

[Provincia: San José] [Sexo: Mujer] [Diversidad: Sexual]

De este recurso se encontraron dos ejemplos en el corpus, uno relacionado con diversidad funcional y otro sobre diversidad sexual. Ambos corresponden a la misma hablante y tienen como función reforzar la verdad de lo dicho, relacionado específicamente con la imagen que la docente construye de sí misma.

En (27), la frase "creo en eso cien por ciento", el numeral refuerza la idea planteada por la docente, a saber, que el afecto constituye un aspecto que considera esencial para el trabajo con estudiantes cuyo nivel de funcionalidad no es el de la mayoría. Por su parte, en (28), plantear que las personas con una orientación/identidad sexual no hegemónica regresan "una y mil y una vez" al hogar de la entrevistada, constituye una forma de hacer inapelable el hecho de ser tolerante hacia dichas personas. A pesar de estos reforzamientos, conviene destacar que esta misma docente plantea lo siguiente respecto a este mismo Volumen 19 Número 1 (Enero-Abril), ISSN 1409-4703 
tópico: “(...) en mi parte de fe (.) yo tengo que darles mi parte (.) y no solamente porque yo quiera (.) sino porque muchas veces esa persona se siente tan perdida (.) que entonces los tengo que llevar ahí $\uparrow($.$) yo les digo (.) te que estás saliendo de donde dios te quiso poner"$ $\{P 4.13\}$.

\subsubsection{Adverbio}

Como se enunció al principio de este apartado, los adverbios que aparecen es esta sección tienen la característica de que no poseen una función nuclear, sino que más bien constituyen elementos modificadores del núcleo. A continuación, se presentan algunas intervenciones que ejemplifican el uso de este mecanismo:

(29) en algunas escuelas hay aula: (.) integrada (.) que está en la misma escuela (.) pero son niños muy muy difíciles que: (.) por ejemplo son muy agresivos (.) que no se pueden tener en un aula $\{\mathrm{P} 1.12\}$

[Provincia: San José] [Sexo: Mujer] [Diversidad: Funcional]

(30) bueno ese tipo de cosas en el aula (.) yo soy una persona muy inclusiva (.) yo: no rechazo ni por raza ni por sexo (.) nada (.) para mí todo el mundo está incluido $\downarrow$ (.) todo el mundo pertenece $\{P 5.15\}$

[Provincia: San José] [Sexo: Mujer] [Diversidad: Funcional]

Los adverbios intensificadores que aparecen aquí corresponden a la estructura "muy + adjetivo" y es posible identificar dos tipos de funciones estratégicas.

En (29), la entrevistada hace referencia al aula integrada, señalando que esta constituye un recurso utilizado para ubicar a los niños "que no se pueden tener en un aula", a los cuales describe como "muy difíciles" y como "muy muy agresivos". En este caso, se busca conseguir el acuerdo del oyente, convencerle de que el aula integrada tiene una razón de ser que es contingente a las características funcionales de determinados estudiantes.

Por su parte, el ejemplo (30), se orienta a hacer creíble lo dicho en relación a la percepción que la docente tiene sobre su manejo de la diversidad sexual. La entrevistada, al plantear que es "sumamente amplia" en relación a dicha temática y señalar además que dicha amplitud es "de toda la vida", refuerza su imagen frente al interlocutor y procura despejar cualquier potencial duda al respecto. 


\subsection{Tropo}

El tropo constituye nuestro último mecanismo de intensificación. Atender a las construcciones metafóricas es importante, pues como señalan Albelda y Fernández (2003) "en numerosas ocasiones, la intensificación falsea la realidad y la manipula, se suspenden las relaciones entre referencia y verdad, con un determinado propósito conversacional" (p. 5). Las figuras retóricas son por lo tanto una vía nada desdeñable para captar los fines comunicativos de un hablante.

A continuación, presentamos dos ejemplos:

(31) yo siempre he ido por ahí (.) esa siempre ha sido mi línea (.) eh siempre antes de que existiera la inclusión ya yo era inclusiva $\{P 5.32\}$

[Provincia: San José] [Sexo: Mujer] [Diversidad: Sexual]

(32) a veces uno dice (.) qué lástima que hasta ahora sé tal cosa (.) y aquel alumno que tuve que tenía eso (.) no lo pude atender en aquel momento eso (.) pero ahí uno va como un vaquero para seguir saliendo avante $\{P 6.33\}$

[Provincia: San José] [Sexo: Mujer] [Diversidad: Funcional]

En (31), estamos frente a un uso metafórico, más específicamente frente a una construcción hiperbólica; la frase "antes de que existiera la inclusión, ya yo era inclusiva", conlleva una intensificación que subvierte justamente la relación entre referencia y realidad. La función que cumple esta construcción, se aboca a convencer al interlocutor de cuán inclusiva es la docente.

Finalmente, en (32), el planteamiento que realiza la docente opera mediante la figura del símil. La construcción "uno va como un vaquero para seguir saliendo avante", evoca distintas imágenes, tales como la del trabajo arduo y constante, e incluso perspicaz que se requiere para el abordaje de lo diverso en el ámbito educativo. En este sentido, la función apunta nuevamente disuadir al oyente respecto a la verdad de lo dicho, que en este caso apunta a mostrar el interés de la entrevistada en el amplio espectro de la diversidad. 


\section{Conclusiones}

A partir de los análisis y las reflexiones generadas a lo largo de esta investigación, planteamos ahora algunos señalamientos de cierre derivados de este proceso, en los cuales se resalta la vinculación del análisis pragmático con los fenómenos sociales objeto de estudio. Si bien es cierto que esta sección se enmarca bajo el título de "conclusiones", los planteamientos presentados aquí no tienen como finalidad hacer un cierre de la discusión planteada, sino más bien generar aperturas para el desarrollo de ulteriores procesos de investigación.

Los procedimientos de intensificación se decantan principalmente por buscar que la persona en función de oyente se alinee con aquella que se encuentra en función de hablante o hacer más creíble lo dicho. En buena parte de los ejemplos analizados, estas funciones se relacionan con auto-descripciones que las personas entrevistadas realizan de su labor como docentes o de la forma en que valoran su percepción sobre las temáticas que son objeto de estudio.

La intensidad de una construcción lingüística es contingente a una valoración escalar que puede decantarse en una dirección ascendente o descendente. Dirimir si un recurso fónico, morfemático, léxico, sintáctico o semántico corresponde a una estrategia de intensificación, requiere el análisis preciso del contexto de las interacciones comunicativas.

Si como se desprende del análisis de resultados, hablar sobre diversidad sexual y funcional conlleva el uso de una gran variedad de recursos lingüísticos de intensificación, podemos argüir que los docentes de primaria del sistema de educación pública costarricense conceden gran importancia a temas relacionados a estas dos dimensiones de la diversidad, en otros términos, que para esta población hablar de dichos temas requiere de una determinada modulación del discurso, que en este caso se refiere a mostrarse cercanos a las temáticas abordadas.

El acreditar esta valoración diferencial respecto al contenido temático, hace plausible el hecho de que exista una mayor tendencia a recurrir a estrategias de acercamiento respecto al mensaje por parte del profesorado, pues dichos arreglos proporcionan diversas prerrogativas a los hablantes que van desde la aceptación por parte del oyente, hasta la evitación de potenciales choques con el interlocutor.

Los usos que los hablantes brindan a las estrategias de intensificación son variados, de tal forma que es posible encontrar dentro del corpus posicionamientos críticos y transformadores sobre los tópicos analizados o planteamientos que van más bien en la 
dirección contraria. En ambos casos, las formas intensificadoras facultan la validación del discurso de los hablantes y de esta forma coadyuvan en la consecución de los fines comunicativos prefijados. La diversidad sexual y la diversidad funcional constituyen temáticas que socialmente resultan polémicas o amenazantes para el personal docente entrevistado. En razón de esta manera de aprehender estos fenómenos sociales, las personas docentes utilizan con frecuencia mecanismos de intensificación para alcanzar fines estratégicos dentro de los procesos de interacción comunicativa.

Tanto los tópicos consignados, como la orientación de las intervenciones realizadas, muestran que en términos generales existen importantes precauciones por parte del personal docente en lo que respecta al abordaje de la diversidad sexual y funcional. Este aspecto sin duda merece atención, dado el rol protagónico que ocupa la figura docente en los primeros años de formación del estudiantado. La pregunta de ¿cómo operan las estrategias de intensificación en el discurso de docentes de primaria del sistema de educación pública costarricense en torno a la diversidad sexual y funcional?, conlleva un problema de investigación de carácter interdisciplinario, que encuentra en nuestro criterio una aproximación de respuesta en el análisis pragmático.

Para precisar este valor de lo pragmático en la presente investigación, un aspecto que conviene traer a colación aquí, se refiere a las funciones comunicativas y al valor enunciativo de las estrategias de intensificación respecto a la construcción de imagen presentes en el discurso de docentes de primaria sobre diversidad sexual y funcional. Para ello, hemos elaborado la Tabla 3 que aparece abajo, con el cual se busca mostrar una aproximación interpretativa de las principales tendencias identificadas a partir del análisis pragmalingüístico de los distintos recursos estudiados. La articulación propuesta conlleva circunscribir las funciones comunicativas y de construcción de imagen a la forma en que es aprehendida la noción de diversidad en el discurso docente, como una forma de extrapolación interpretativa.

Tabla 3

Síntesis de funciones comunicativas y construcción de imagen a partir del análisis de recursos de intensificación

\begin{tabular}{|c|c|}
$\begin{array}{c}\text { Hacer más creíble lo dicho: } \\
\begin{array}{c}\text { Reforzar la verdad de lo dicho } \\
\text { Yo acepto la diversidad }\end{array}\end{array}$ & $\begin{array}{c}\text { Búsqueda de acuerdo en el } \\
\text { oyente: Conseguir que el que } \\
\text { oyente esté de acuerdo y se } \\
\text { alinee con el hablante }\end{array}$ \\
& $\begin{array}{c}\text { Esto que digo, es evidencia de } \\
\text { que acepto la diversidad }\end{array}$ \\
\hline
\end{tabular}

Fuente: Elaboración propia, 2017. 
Los distintos ejemplos que aparecen en el apartado de Análisis de resultados, muestran que mayoritariamente las personas docentes procuran mostrar una posición de apertura y tolerancia respecta al abordaje de la diversidad funcional y sexual. Argüimos en este sentido que las estrategias de intensificación, coadyuvan a la realización de los fines estratégicos que figuran los cuadrantes dentro del marco de la interacción comunicativa que conlleva el proceso de entrevista.

Siguiendo a Bravo (2003), "la identidad personal del "yo" (self) es un conjunto de cualidades sin las cuales un individuo no puede imaginarse a sí mismo (noción psicológica); en lo social, el "yo" es un conjunto relativamente estable de percepciones acerca de quiénes somos en relación con nosotros mismos, los otros y los sistemas sociales" (p. 100). De tal forma que las interacciones interlocutivas son también representantes o estandartes de ese "yo" frente al mundo.

De acuerdo con Briz (2004), "los factores enunciativos atienden a los componentes de la enunciación, esto es, a los elementos que definen un acto de habla como hecho lingüístico en uso. El estudio pragmático exige valorar cómo se integran los elementos de la enunciación: algo que se dice por alguien con la intención de hacer algo en la lengua" ( $p$. 33). En este sentido, planteamos que la forma específica de aprehender el lenguaje por parte del profesorado, permite comprender una variedad de aspectos culturales y políticos que están inscritos en ese marco institucional que llamamos Escuela.

Habiendo arribado a este punto, diremos, a modo de reflexión final, que el vestigio de concepciones moralistas sobre la sexualidad en personas jóvenes, así como la idea de la homogenización en torno a la funcionalidad corporal, representan hoy en día verdaderos escollos con miras a cualquier intento de transformación de ese marco institucional, pues si no se reconoce la autonomía de los y las estudiantes sobre sus propios cuerpos en sus diferencias múltiples, difícilmente la presencia del niño afeminado, la niña marimacha, las relaciones homoeróticas o los niños y las niñas en silla de ruedas, con baja visión o sordera, serán asequibles en la economía simbólica del espacio educativo. Las apreciaciones vertidas en las entrevistas por el profesorado en relación a la diversidad sexual y funcional, muestran que queda un largo camino por recorrer para que los espacios escolares lleguen a convertirse en espacios inclusivos en los que se haga realmente factible el reconocimiento del otro en su alteridad. 


\section{Referencias}

Albelda, Marta. (2004). La escalaridad en la intensificación. Interlingüística, (15), 105-114.

Albelda, Marta. (2005). La intensificación en el español coloquial (Tesis Doctoral en Filología Hispánica). Universitat de València, Valencia, España.

Albelda, Marta. (2004). La escalaridad en la intensificación. Interlingüística, 15, 105-114.

Albelda, Marta y Álvarez, Alexandra. (2010). Los corpus discursivos en el estudio prágmático de la atenuación y de la intensificación. Revista Internacional de Lingüística Iberoamericana, 8(16), 79-100.

Albelda, Marta, Briz, Antonio, Cestero, Ana María, Kotwica, Dorota y Villalba, Cristina. (2014). Ficha metodológica para el análisis pragmático de la atenuación en corpus discursivos del español (es.por.atenuación). Oralia: Análisis del discurso oral, (17), 7-62.

Albelda, Marta y Fernández, María José. (2003). Intensificación y metáfora. Actas del XXIII Congreso Internacional de Lingüística y Filología Románica, 2(1), 3-8.

Arce, Ángela. (1999). Intensificadores en el español coloquial. Anuario de Estudios Filológicos 22, 37-48.

Bravo, Diana. (2003). Actividades de cortesía, imagen social y contextos socioculturales: una introducción. En Diana Bravo (Ed), La perspectiva no etnocentrista de la cortesía: identidad sociocultural de las comunidades hispanohablantes. Actas del Primer Coloquio del Programa EDICE (pp. 98-108). Estocolmo: Universidad de Estocolmo, Departamento de Español, Portugués y Estudios Latinoamericanos.

Briz, Antonio. (2003). La estrategia atenuadora en la conversación cotidiana española. En Diana Bravo (Ed), La perspectiva no etnocentrista de la cortesía: identidad sociocultural de las comunidades hispanohablantes. Actas del Primer Coloquio del Programa EDICE (pp. 17-46). Universidad de Estocolmo, Departamento de Español, Portugués y Estudios Latinoamericanos.

Briz, Antonio. (2004). Cortesía verbal codificada y cortesía verbal interpretada en la Conversación. En Diana Bravo y Antonio Briz (eds.), Pragmática sociocultural: Estudios sobre el discurso de cortesía en español (pp. 67-93). Ariel, Barcelona.

Charaudeau, Patrick y Maingueneau, Dominique. (2002). Diccionario de análisis del discurso. Madrid: Amorrortu Ediciones.

Cid, Miriam y Maluenda, Lorena. (2005). El alargamiento segmental en el habla pública de Chile. Comportamiento prosódico-discursivo. ONOMÁZEIN, 11(1), 43-55.

Conte, Jorge y Zamora, Carlos. (2008). Derechos Humanos Costa Rica. Panorama actual sobre las organizaciones sociales. Red de Organizaciones de Derechos Humanos, Centro para la Justicia y el Derecho Internacional (CEJIL). Recuperado de http://lib.ohchr.org/HRBodies/UPR/Documents/Session6/CR/JS1 CRI UPR S06 2009 Annex1 S.pdf 
Corpas, Gloria. (1997). Manual de fraseología española. Madrid: Editorial Gredos.

Davis, Lennard. (2000). Enforcing Normalcy, Disability, Deadness and the Body. London: Verso.

Fernández, Daniel. (2016). Teoría queer y teoría crip: reflexiones teóricas en relación con el ámbito educativo. En Wanda Rodríguez, Maurizia D’Antoni y Victoria González. (Comp.), Vygotski: Su legado en la investigación en América Latina (pp. 77-91). San José: Universidad de Costa Rica.

Ferrer, María-Cristina y Sánchez, Carmen. (1998). Diálogo coloquial: la atenuación. Oralia, (1), 213-222.

Fuentes, Catalina. (2006). Operadores de intensificación del adjetivo: los cuantificadores escalares. Anuario de Estudios Filológicos, 29, 35-53.

Gatto, John-Taylor. (2001). Underground History of American Education. Nueva York: The Oxford Village Press.

González, José-Manuel. (1984). Sobre la expresión de 'lo superlativo' en español. En IV Anuario de Estudios Filológicos (pp. 101-132). Recuperado de http://dehesa.unex.es/bitstream/handle/10662/4484/0210$8178 \quad 7$ 173.pdf? sequence $=1$ \&isAllowed $=y$

Grosz, Elizabeth. (1996). Intolerable Ambiguity: Freaks as/at the Limit. In Rosemarie GarlandThomson (Ed.), Freaky: Cultural Spectacles of the Extraordinary Body (pp. 55-68). New York: New York University Press.

Gutiérrez, Salvador. (2000). Temas, remas, focos, tópicos y comentarios (Cuadernos de Lengua Español, 46). Madrid: Arco Libros, S. L.

Herrero, Gemma. (1991). Procedimientos de intensificación ponderación en el español coloquial. Español Actual, (56), 39-51.

Hidalgo, Antonio. (2015). Prosodia y partículas discursivas: Sobre las funciones atenuación, intensificación como valores (des)corteses en los marcadores convencionales. Círculo de Lingüística Aplicada a la Comunicación (clac), 62, 76-104.

Hidalgo, Antonio. (2011). Humor, prosodia e intensificación pragmática en la conversación coloquial española. VERBA, 38, 271-292.

Martín, Josefina. (1998). Los prefijos intensivos del español: caracterización morfosemántica. Estudios de Lingüística de la Universidad de Alicante, (12), 103-116.

McRuer, Robert. (2006). Crip Theory. Cultural Signs of Queerness and Disability. New York: New York University Press.

Montecino, Lésmer. (2004). Estrategias de intensificación y de atenuación en la conversación coloquial de jóvenes chilenos. ONOMÁZEIN, 10(2), 9-32. 
Palacios, Agustina y Romañach, Javier. (2006). El modelo de la diversidad. La bioética y los derechos humanos como herramientas para alcanzar la plena dignidad en la diversidad funcional. España: Ediciones Diversitas.

Penas, María Azucena. (2009). Cambio semántico y competencia gramatical. Madrid: Iberoamericana.

Real Academia Española. (2011). Nueva gramática de la lengua española. Fonética y fonología. Barcelona: Espasa Libros.

Reguera, Alejandra. (2008). Metodología de la investigación lingüística. Prácticas de escritura. Córdoba: Editorial Brujas.

Roca, Francesc y Suñer, Avel-Lina. (1998). Reduplicación y tipos de cuantificación en español. Estudi General 7, pp. 37-66.

Ruiz, Leonor. (1998). La fraseología del español coloquial. Barcelona: Ariel.

Van Dijk, Teun. (1990). La noticia como discurso. Comprensión, estructura y producción de la información. España: Paidos. 